\title{
Exploring Accounting Teachers' Views on the Quality of Accounting Prescribed Textbooks in South Africa
}

\author{
Jabulisile C. Ngwenya and S'khumbuzo H. Mbili \\ University of KwaZulu-Natal, South Africa \\ https://orcid.org/0000-0001-8256-8174 \\ https://orcid.org/0000-0002-9012-1820
}

\begin{abstract}
Textbooks are regarded as the primary conduits for delivering knowledge content to the students. As a result, teachers base their lesson plans on the material given in textbooks to ensure the effectiveness of instruction. This study focuses on teachers' views on the quality of grade 12 Accounting prescribed textbooks. An interpretive, qualitative case study design was employed to get an in-depth understanding of teachers' views. We used semi-structured interviews to obtained data from ten purposively selected Accounting teachers. What emerged from the findings is that, although textbooks are aligned with the curriculum in terms of topics covered, teachers found textbooks wanting in guiding and supporting teachers with regard to teaching new content and assessment activities. A lack of support and guidance in textbooks compelled teachers to use other support materials to compensate for the shortfalls in the prescribed textbooks. The study recommended that more than one prescribed textbook should be bought for students. In addition to the prescribed textbooks, teachers should be provided with more books for consultation during lesson preparations and teaching. Other learning and teaching support materials should be made available to avoid heavy reliance on textbooks.
\end{abstract}

Keywords: Accounting teachers; Accounting prescribed textbooks; quality textbooks

\section{Introduction}

The quality of the education system depends on the quality interaction between students and teachers through the use of learning and teaching resources. Teachers regard textbooks as one of the significant resources that they need to deliver content effectively. Studies globally show that the majority of teachers routinely used textbooks since they provide them with teaching strategies, activities and assessment tasks (Chirwa \& Naidoo, 2016; Freahat \& Smadi, 2014; Swanepoel, 2010; Tarmana \& Kuran, 2015). Textbooks are regarded as an essential instructional material used for teaching and learning. The implication is that in 
many countries textbooks are used by teachers as the predominant source of teaching and learning activities. As a result, they have turned out to be the curriculum on which teachers rely (Freahat \& Smadi, 2014; Morales \& Baker, 2018; Tarmana \& Kuran, 2015). Thus what is taught in the classroom is predominantly guided, organised and restricted to what is contained in the textbook.

In South Africa, the Minister of Basic Education emphasised the critical role of textbooks in schools as a dominant resource to maintain the implementation of the Curriculum and Assessment Policy Statement (CAPS). In its attempt to improve the quality of education in South Africa, textbooks were being reintroduced in classrooms as a crucial resource for students and teachers as one of the ways of improving teaching and learning. This is supported by Yang and Sianturi (2017), who stressed that during the process of educational reform textbooks are used to support teachers in the enactment of the curriculum as they offer appropriate pacing and weighting of content. Consequently, textbooks are regarded by the Department of Basic Education (DBE) as an 'effective tool that is being used to ensure consistency, curriculum and assessment scope, suitable pacing and better quality in terms of teaching in implementing a curriculum' (Department of Education (DoE), 2009, p.9). As such, textbooks strongly influence what students learn because they help teachers decide what to teach, how to teach it, and what types of exercises to assign to students. As textbooks are viewed as the most effective tools through which to deliver the curriculum and support assessments, textbooks need to be aligned with the recognised curriculum (Sunday, 2014).

However, while the Department of Basic Education stresses the use of textbooks as the primary resource for teachers, shortage of textbooks still persists in South Africa. Despite the DBE recommendation that teachers should use of a minimum of three textbooks in planning and teaching (DBE, 2011), in several schools, especially in the disadvantaged context, only one textbook is prescribed for both teachers and students due to financial constraints. As a result, teachers often depend excessively on the prescribed textbook.

The prominence of textbooks is also apparent in Accounting. Accounting is a discipline that requires consistent practice due to its practical nature (Barac \& du Plessis, 2014; Erasmus \& Fourie, 2018; Myers, 2016). As the subject requires frequent application exercises, textbooks are expected to support teachers and students in the learning process with suitable activities and a wide range of examples that support students' reflection (Adeoye \& Olabiyi, 2011). Furthermore, the Accounting curriculum requires students to participate in effective learning that enhances creative, problem solving and critical thinking skills (Barac \& du Plessis, 2014; DBE, 2011). These skills are expected to be delivered by the textbooks that are being used in schools.

However, in many schools in South Africa, teachers are likely to rely heavily on textbooks as they are the only source of information for content to be taught. While the practical nature of the subject compels Accounting teachers to give students a variety of assessment tasks, teachers often find it challenging to use 
textbooks sparingly or supplement with other materials due to a shortage of adequate resources. As a consequence, most teachers, including new teachers, treasure textbooks as their sole teaching and learning resource. This is because textbooks provide teachers with class activities and homework to allow students to practice different skills learned in class (Davidson \& Baldwin, 2005; Myers, 2016; Terblanche \& de Clercq, 2020). Because textbooks are likely to be the critical definers of what is taught and learnt, teachers are more likely to follow closely what is offered in the textbook. In addition, the subject Accounting has been overwhelmed with recurring curriculum changes due to global changes in Accounting standards. As the Department of Basic Education regards textbooks as useful tools for curriculum delivery, textbooks should provide teachers with adequate support and guidance in teaching the new topics effectively. Although textbooks are an integral element in the educational process, there is still considerable debate on the quality of prescribed textbooks. Since Accounting teachers are known to rely on textbooks (Terblanche \& de Clercq, 2020), it is imperative that quality of textbooks be investigated to ascertain the extent to which they contribute to attaining the desired learning objectives.

While there is substantial literature on textbooks internationally (Cho, 2017; Morales \& Baker, 2018; Liang \& Cobern, 2013; Lin \& Yang, 2015; Sunday, 2014; Tarmana \& Kuran, 2015; Yang \& Sianturi 2017), few studies have been embarked on textbooks in South Africa (Arek-Bawa \& Dhunpath, 2017; Bargate, 2012; Bharath, 2015; Chirwa \& Naidoo, 2016). Furthermore, literature shows that there is a shortage of research on the quality of Accounting textbooks. This consequent paucity makes the findings reported in this paper particularly remarkable as the study adds to knowledge by filling in the gap in the current literature in Accounting, especially on teachers' views on the quality of prescribed textbooks. The research is guided by the following question: What are the Accounting teachers' views on the quality of the grade 12 Accounting prescribed textbooks?

\section{Literature review}

In order to shed light on the teachers' views on the quality of Accounting textbooks, the relevant literature on the importance of textbooks in teaching and learning, the nature of the Accounting subject and the use of textbooks and the quality of textbooks and characteristics of a quality textbook will be reviewed. Furthermore, literature on the preceding studies on teachers views on the quality of textbooks will be provided.

\subsection{Importance of textbooks in teaching and learning}

Fan (2013) and Gök (2012) view a textbook as a pool of the knowledge, ideas, concepts, and values of a particular topic which is usually written by education specialists who are experts in a particular field. Literature shows that textbooks assist in the implementation of curriculum reforms because textbooks support teachers in the interpretation and execution of the curriculum (Chirwa \& Naidoo, 2016; Freahat \& Smadi, 2014; Yang \& Sianturi, 2017; Tarmana \& Kuran, 2015). Textbooks are often used as a curriculum guide and the primary organiser of the content that students are required to learn. Therefore, textbooks convey thorough explanations of topics to be taught. In other words textbooks link the planned 
curriculum to the enacted curriculum or implemented curriculum (Fan, 2013; Swanepoel, 2010). This implies that the utilisation of the textbook in teaching and learning will ensure that the objectives of the curriculum are reached and the students understand the content of the subject.

Students' opportunities to learn are largely determined by textbooks as they often directly influence teachers' choice of content and instructional strategies (Fan, 2013; Lin \& Yang, 2015). The textbooks help teachers to organise their teaching by identifying the topics and also attempt to specify how classroom lessons can be structured with suitable exercises and activities. In this way, textbooks give teachers the opportunity to provide their students with more content knowledge, examples and assessment activities. It is therefore important for teachers as facilitators of learning to be conscious of the quality and limitations of the prescribed textbooks because the quality of textbooks has a significant influence on the quality of teaching.

\subsection{The nature of the Accounting subject and the use of textbooks}

In Accounting, textbooks are regarded as the most commonly used teaching and learning support material as it entails a specific form of practice and instruction (Abbott \& Palatnik, 2018; Erasmus \& Fourie, 2018; Pereira \& Sithole, 2020). This is because learning in the subject occurs mostly through the regular practice of different skills due to the practical nature of the subject. (Erasmus \& Fourie, 2018; Myers, 2016). Accounting textbooks provide an important source of material for reviewing and recapping the lessons taught in the class. It therefore, encourages self-study and independent work among the students which is of utmost importance in a practical subject like Accounting. Consequently, Accounting textbooks provide extra opportunities for students to do their work independently at their own pace to cover the complex nature of the subject and to expand conceptions of the discipline (Abbott \& Palatnik, 2018).

According to Barac and Du Plessis (2014), students should be given a range of assessment tasks to equip them with a variety of skills. In Accounting, the first skill that learners should acquire is the understanding of concepts. Mastering concepts serves as a basis for application, analytical and evaluation skills in each Accounting topic (DBE, 2011). The textbooks provide clear definition of such key concepts and core knowledge while providing clear learning progressions. This encourages students to understand financial concepts and increase their knowledge by providing activities that promote critical thinking skills. The implication is that frequent exposure to financial problems and scenarios is essential for students to develop capability and the skills. This entails teaching approaches that stimulate active student learning through projects, problemsolving, case studies and authentic scenarios (Pereira \& Sithole, 2020; Tarmana \& Kuran, 2015). It is assumed that prescribed Accounting textbooks should have these activities.

As the subject Accounting is hierarchical in nature, textbook provides insight to the teacher in planning lesson as it helps him to decide about the limits and depth of coverage of the content to be presented to the students while teaching. The 
logical and psychological sequencing followed in a textbook helps the teachers in presenting the subject matter in an orderly and systematic sequence. This further shows the importance of the textbook in Accounting as a subject. It is for this reason that the teachers' views regarding the quality of these textbooks need to be explored.

\subsection{Teachers views on the quality of textbooks}

Extensive research has been conducted to investigate the quality of textbooks from the teachers' viewpoint in History, Geography Biology, Science, Mathematics and English. Fan (2013), Lin and Yang (2015); Kimmons (2015), Salam and Shahrill (2015), Sunday (2014), and Yang and Sianturi (2017) conducted studies on teachers' views and perceptions of quality of Maths textbooks. Kimmons (2015), in his study teachers indicated that the textbooks they used in teaching Mathematics in Turkey do not have a good quality of activities for examination preparation. He found that textbooks provided insufficient activities to prepare the students to pass exams. Similarly, in Yang and Sianturi's (2017) study, most teachers in Singapore felt that Maths textbooks do not have enough activities for learners to practice and this was having an impact on learning. Salam and Shahrill (2015) in Singapore found that Maths textbooks had more higherorder level questions on linear function topics. On the contrary, Yang and Sianturi (2017) found that teachers were concerned about the level of cognitive demand for assessment in mathematics textbooks. While the textbooks covered all the content and concepts adequately, trigonometry textbooks contain questions that largely entail lower levels of cognitive demand. The concern was that such textbooks do not enhance student learning since students are seldom asked to tackle challenging problems.

Janko and Knecht (2013); Lee and Catling (2016); Tarmana and Kuran (2015); Yang, Wang and Xu (2015) did studies on Geography textbooks. Tarmana and Kuran (2015) conducted a study on Social Studies textbooks. They found that textbooks contained insufficient higher-order cognitive level questions. Similarly, Lee and Catling (2016) found that there was a scarcity of assessment tasks in Junior Geography textbooks in the United Sates. Teachers were worried that a shortage of activities in textbooks is probably restricting students' opportunities to improve different abilities and skills unique to Geography. Like Lee and Catling, in Yang, Wang and Xu's (2015) study, Geography teachers in secondary schools in China had difficulties in assigning extra classwork or homework to nurture and reinforce what learners have learned in class due to a shortage of activities. Janko and Knecht (2013) examined the visuals included in Czech geography textbooks and found that realistic visuals were dominant in Czech geography textbooks. However, Lee and Catling (2016) found that there were few visuals in geography textbooks. Furthermore, there were no connections between subject matter and visuals like pictures that are meant to help learners understand new content.

Morales and Baker (2018) conducted a study on teachers' views on Open Science textbooks. They found that science textbooks were lacking severely in terms of content coverage. Although topics were mentioned, textbooks content had not 
been covered thoroughly. Contrary to Morales and Baker, Cho (2017) investigated teachers' beliefs about Biology textbooks and found that textbooks were aligned to the curriculum in terms of content. Although the end of chapter assessments were according to students' mental development level, teachers found textbooks lacking in terms of real-life activities.

Liang and Cobern (2013) investigated the teachers' perceptions on the quality of the New Interchange English textbook. They found that the teachers were of the same opinion that the content of the textbook was challenging, inspiring and pertinent to students' development. However, they were not satisfied with the layout of the textbooks since they were not organised appropriately (Liang \& Cobern, 2013). Their study is in line with Freahat and Smadi's (2014) study on teachers' perspectives on the English textbooks in Jordan who found that textbooks appeared to be wanting in terms of layout. They suggested that textbooks need to be revised regarding its layout and design.

The literature reviewed shows that there is a shortage of studies on teachers' perceptions and views on the quality of Accounting textbooks.

\subsection{Characteristics of a quality textbook}

A good textbook is one that has the characteristics and features that allow it to support both students and teachers during the process of learning and teaching (Chirwa \& Naidoo, 2016; Terblanche \& de Clercq, 2020). Because textbooks have a strong influence on the effectiveness of instruction, a textbook is of good quality if the students who use the textbook achieve the learning outcomes they are supposed to attain (Swanepoel, 2010). In this regard, the availability of good textbooks is one of the key elements in the effective implementation of curriculum transformation (Chirwa \& Naidoo, 2016; Swanepoel, 2010). Furthermore, research has shown that textbooks should comply with the curriculum with regard to content, learning activities and assessment, layout and teacher guidance (Aggarwal, 2001; Swanepoel, 2010). According to Aggarwal (2001), the quality of textbooks could be evaluated on organisation and presentation of content, verbal and visual communication. For this article, teachers' views were explored on the guidance and support provided by textbooks in teaching and learning in terms of how they reflect the requirements of the CAPS curriculum as regards to topics coverage, explored on the guidance and support provided by textbooks in teaching and learning in terms of sequencing of topics, background information, learning objectives, motivational strategies and learning and assessment activities.

\section{Methodology}

The interpretive qualitative case study approach was considered suitable for this study as we were interested in understanding the meaning teachers have constructed in making sense of the quality of their prescribed textbooks (Cohen, Manion \& Morrison, 2018). We believe that there are multiple meanings to a phenomenon that are socially-constructed. The researcher construct meaning of data from his viewpoint (Marshall \& Rossman, 2014). We adopted a qualitative case study design since the aim was to gain an in-depth understanding of 
Accounting teachers' views (Cohen et al., 2018; Marshall \& Rossman, 2014). In the case study, the main assumption is that the phenomenon is investigated as a bound system (Creswell, 2014). In this study, the bound system was a group of ten Accounting teachers.

\subsection{Sampling}

In this study, ten teachers who were teaching Accounting in Grade 12 were purposively selected from ten schools that were conveniently sampled in the Hibiscus coast District in KwaZulu-Natal. The number of participants is supported by Schulze (2003), who writes that in a qualitative research study only a few participants are involved because it aims at understanding and describing a phenomenon as it develops in a natural setting.

\subsection{Data generation}

Semi-structured one-on-one interviews were used to probe the Accounting teachers' views on the quality of textbooks. The participants' workplace was used to conduct interviews during their free periods. Each interview took approximately 45 minutes. These interviews were recorded and transcribed verbatim to ensure that the participants' views were captured correctly during transcribing. Participants' views on the quality of textbooks were supplemented through teacher reflective journals. Teachers were asked to write their views in their personal journals.

\subsection{Data analysis}

The data set obtained from semi-structured interviews was analysed using thematic analyses (Cohen et al., 2018). The process of analysing data began by write out audio-data to textual-data. We then read the transcripts numerous times to identify units of meaning, in order to access the deeper meaning of the responses received. During the process of open coding, categories were identified, revised and gathered into particular themes that were used to report the findings. Reflective journals were then analysed using themes that were developed from the interviews

\subsection{Ethical consideration}

The ethical code of conduct was adhered to by acquiring permission to conduct the research from the university where the authors are based. Other ethical procedures which included informed consent, confidentiality and anonymity, and voluntary participation were explained to the participants and adhered to throughout the duration of the study. All participants were kept anonymous by giving them pseudonyms.

\section{Findings}

The study aimed to explore teachers' views on the quality of prescribed Accounting textbooks. During the process of analysing the data gained from semistructured interviews, the literature on characteristics of quality textbooks were used to develop the themes. To discuss the findings in this paper, we draw on three themes that emerged during data analysis. These themes are as follows: Textbooks' alignment with the curriculum, the support provided by textbooks in teaching new concepts and guidance and support in terms of assessment 
activities. In the presentation of our findings, verbatim quotes are given to ensure that the views of teachers are not lost.

\subsection{Textbooks' alignment with the curriculum}

Teachers were asked about their views on the alignment of the Accounting textbooks with the Accounting curriculum. The findings revealed that the main topics in the textbooks are covered according to the curriculum stipulation. Teachers, therefore, viewed textbooks as the supplementary resources to the curriculum. However, they were concerned with sequencing and inadequate information in other textbooks.

\subsubsection{Topics and content coverage}

The teachers' views were unanimous concerning how topics were covered in their textbooks about the specification in the Accounting curriculum. They were all satisfied with the coverage of topics in their prescribed textbooks. Miss Nkomo indicated that her textbook contains all topics as stipulated in the Accounting curriculum: 'Most textbooks cover all the topics that are in the Curriculum and Assessment Policy Statement (CAPS). All topics are listed in the table of content like in the CAPS'.

While teachers were content with the alignment of the textbooks with the curriculum in terms of coverage of the main topics, teachers voiced concerns regarding the coverage of content within the main topics. Teachers indicated that some other textbooks did not have sufficient content, and as a result, they find it problematic to prepare lessons. Miss Gusha expressed her dissatisfaction regarding inadequate information in her prescribed textbook. This shortcoming forced her to use more than one textbook to teach: 'Textbooks do cover all the content, but in some cases, you will find that a certain textbook explains much better than the other textbook.'

Teachers were apprehensive about insufficient content on the new topics found in the textbooks. They believed that Accounting textbooks should give students a detailed background to lay a solid foundation during the introduction of new topics. Mr Nyathi indicated that while the new topics appear in the textbooks, the information provided is not comprehensive enough for students to understand the topic. In addition, textbooks do not give the teachers sufficient content required to explain the topics thoroughly in class: 'The topic is there; the buyback of shares is not explained clearly.' Furthermore, while teachers are expected to prepare students for examinations, some new topics do not appear at all in the Accounting textbooks. Miss Nala expressed her disappointment: 'We were told that Shareholding would be examined, but it is not in the textbooks. We use exam guidelines.'

Teachers indicated that the information that is provided in the textbooks in outdated and deceptive. Some of the scenarios found in the textbooks are based on the old information. Teachers added that some prescribed books are ragged and falling apart as they were bought while the new curriculum was implemented in 2013 and schools are struggling financially to replace textbooks. 


\subsubsection{Sequencing of topics}

The sequencing of topics in textbooks supports the learning of new knowledge by helping teachers present the learning material in a logical order. However, teachers found most textbooks to be misaligned with regard to the structure, as they do not follow the same sequence as the Accounting curriculum. Most of the textbooks were found elusive in terms of helping teachers with the sequencing of their teaching. Miss Ndlovu said that: 'In other textbooks the topics are mixed. Topics are not arranged according to the CAPS and this is not helping us when teaching. That is why we use examination guidelines'.

Teachers believed that chronological presentation of information is vital for students' ability to understand what they are learning. Without a sequence in the delivery of information, students could miss important details and remain confused.

\subsection{Support provided by textbooks in teaching new concepts}

\subsection{Learning outcomes and introductory information}

While a textbook is expected to assist students achieve the learning objectives they are required to reach, teachers were concerned about their textbooks because they failed to provide learning outcomes. They expressed their dissatisfaction that they have to constantly consult with the curriculum because textbooks do not give them guidance in terms of depth of topics by outlining explicit learning outcomes. This is what Miss Nyoka said: 'There are no learning outcomes and there is nothing in the textbook that guides me on how deep I must go with the teaching. I use my experience'.

Due to the absence of specific learning outcomes in the textbooks, teachers often resorted to their own experience and understanding of the subject when teaching particular topics.

Teachers indicated that some books have a checklist at the end of the chapter to summarize the learning outcomes. Teachers were of the view that there is a huge relationship between the learning objectives of the chapter and the checklist. They firmly believed that textbooks should have objectives at the beginning of the chapter and checklist at end of the chapter to guide and assist in verifying and ensuring that all subtopics have been taught. Mr Ndlovu said that: 'If textbooks do not have checklists at the end of the topic, it disadvantages both students and teachers because you need to check if you have covered everything in the topic. We end up using CAPS and the ATP'.

The absence of learning outcomes and checklist in the textbooks is misleading because teachers could not verify the content coverage within the topic. Hence teachers relied heavily on the CAPS and the ATP.

\subsubsection{Information on new concepts}

In Accounting, understanding of concepts is essential for students to be able to interpret financial information. Teachers felt that understanding of Accounting concepts depends on the information found in the textbooks. What is remarkable is that prescribed textbooks do not provide a detailed explanation of the unique concepts. Mr Gama confirms this: 'Textbooks should give students depth knowledge about new Accounting terminology. Definitions are there but are not giving full 
information.' While textbooks were expected to provide detailed information on concepts, they fall short in providing teachers with adequate information on the new concepts.

\subsubsection{The use of visuals in teaching and learning of new concepts}

Textbooks should use different types of visuals to assist in reminding teachers and students of the critical information on the topic. Teachers stated that textbooks gave them less support concerning signifying the important information. Miss Nene added that their textbooks have little indicators like bold words that caution them with respect to the important concepts or information: 'In my textbooks there is a very minimal indication, if the concepts are written in bold, it sends a message to the learner that this word is important'. Miss Jobe indicated that her textbook has key or word boxes that alert her of essential concepts. Teachers specified that if the information or concepts are written in boxes on the side of the text, it draws the students' attention.

Some teachers pointed out that their textbooks use different visuals, although they were not introduced at the beginning of the textbook to give clarity on its meaning and how they are used in the textbooks. Because they have been using the textbooks for a long time, they know that essential concepts or information were emphasised in small boxes and sometimes written in bold.

Additionally, Miss Nkomo revealed that her textbook also has graphics in the form of pictures. These pictures assisted in explaining important information. However, they were blurry since they were in black and white: 'There are pictures in my book, sometimes they give me more information, but they are in black and white'.

Other teachers added that in their textbooks there were cartoons that reminded them about the new terms. Mr Josephs further alluded to the type of cartoon that was found in one of his textbooks that highlighted the important information: 'In the format of cash-flow statement, there is a cartoon of an elephant. That on its own makes me know that this information is important'.

Teachers believed that graphics assisted students in better comprehending what they are learning because a picture stays much longer in memory and this helps students to recall new content, especially if they understand the meaning of the graphics.

\subsubsection{Linking new content to students' experience and prior knowledge}

They usually consulted other textbooks when preparing the new topic as they cannot rely on the prescribed books only because they have limited information on different topics. Mr Ndlovu added that using more textbooks in addition to the prescribed one allowed him to formulate diverse strategies when explaining in class: 'The information is there but I think it is not sufficient for my teaching and that is why I sometimes combine all of them during the introduction of the new topic'.

It is imperative in Accounting to relate unique concepts to students' experience when introducing and clarifying new knowledge. Teachers encountered difficulties when introducing new chapters as the textbooks had insufficient 
information to allow them to use students' experiences to expand on their explanations. Teachers' felt that other topics in Accounting are not easy to relate to students' experiences as a result they use examples that are not familiar to students. They believed that it depends on the topic they were introducing. To confirm this, Mr Gama responded: 'Other topics are complicated to introduce using what students know. Even in the textbook, there is no simple clarity on Debtors and Creditors reconciliations in the textbooks'.

Teachers raised concerns about information that is provided by textbooks in terms of prior experience that a learner is expected to have before attempting the new topic. Teachers' responses revealed that textbooks fell short in providing support regarding previous knowledge required in learning new knowledge.

Miss Nala further outlined that textbooks are not the same. Some textbooks allow students to use their experiences as they use examples from what students see or practice almost every day: 'The textbook gave an example of sand and cement in the manufacturing of blocks when teaching manufacturing'.

Teachers believed that it hinges on the textbook that is used by the individual teacher. They made mention that this particular textbook gave good support and guidance compared to all other prescribed textbooks they are currently using. The textbook provides a detailed introduction that gives an outline of what is covered in each topic. The textbook also offers in-depth background information about the sub-topic. Furthermore, at the beginning of each topic, teachers are reminded of the prior knowledge that a learner is expected to have before attempting the new topic. Ms Nene also enunciated that the textbook also provided revision activities to remind students of the previous knowledge and to assess their readiness for the new chapter:

"In the introduction of financial statements, you will find that textbooks start with activities on theory to remind students that in Grade 10 and 11, they were introduced to the financial statement. I have to buy my copy."

However, teachers expressed concern that the textbook which gives them adequate support and guidance is expensive and the schools cannot afford to prescribe it for students because of financial constraints.

\subsection{Guidance and support in terms of assessment activities}

Teachers specified that prescribed textbooks did not have enough activities to allow students to review what has been learnt in class. Teachers expressed their worries about the shortage of activities. Further, they mentioned that the textbooks were incompatible with the requirements of the Annual Teaching Plan in terms of the number of assessments for each topic:

"The activities are not enough, you will find that CAPS requires you as the teacher to give students eight activities but the textbook has five activities. That is why I use previous question papers". (Miss Gusha)

Teachers shared the same sentiments concerning the support given by textbooks in preparing the students for external examination. They were worried that 
activities found in their textbooks did not match the standard of questions in the NSC examination papers in terms of level of challenge.

"In the exam you will find that students are expected to fill in the missing figures in the balance sheet and such activities are not there in the textbooks, the standard of the activities is very low". (Miss Nyoka)

Findings revealed that most textbooks have creative and problem-solving activities that allow students to make evaluative judgements using the financial information provided, although they were insufficient. However, teachers were concerned that textbooks do not have creative real-life problem solving questions that require students to identify problems from a range of financial information.

\section{Discussion}

Findings revealed that prescribed textbooks were aligned with the curriculum in terms of topics coverage. While teachers viewed textbooks as complements for the curriculum, teachers found them deficient in terms of information required to teach the new content adequately. In Accounting it is crucial that regular revision of teaching resources and textbooks are done to incorporate current Accounting standards and legislations in order to familiarize students and teachers with the authenticities (Bargate, 2012; Ngwenya \& Arek-Bawa, 2019). However, findings revealed that most textbooks had insufficient information on the new topics.

The Accounting curriculum emphasises conceptual coherence, sequence and progression of knowledge in a manner that assists the teachers with planning and teaching and to facilitate ease of comprehension (Arek-Bawa \& Dhunpath, 2017; Bharath, 2015; DBE, 2011). However, in this study teachers indicated that textbooks were misleading in terms of helping teachers in structuring teaching in a logical order. This finding is supported by the views of teachers in Yang and Sianturi, 2017 who found that the content or the topics in the instructional materials were not properly arranged or sequenced. They believed that a disarray of topics hinders students' ability to understand what they were learning.

Findings revealed that prescribed textbooks were unsuccessful in supporting teachers in introducing new topics and providing learning outcomes. In this regard, Freahat and Smadi (2014) assert that textbooks are expected to consistently provide a detailed introduction with clearly stated learning outcomes at the beginning of the topic to focus all instructional and assessment and to consolidate learning. This gives guidance on how deep the teachers are expected to go when teaching the topic.

Research shows that effective learning happens when students are able to use existing knowledge to learn the new concepts (Arek-Bawa \& Dhunpath, 2017; Freahat \& Smadi, 2014; Ngwenya \& Arek-Bawa, 2019). In this study, teachers were of the view that most prescribed textbooks were silent in terms of reminding students of foundational knowledge needed to learn new knowledge. This finding is similar to Sunday (2014) study who found that mathematics teachers often struggled when introducing new topics because of insufficient background information on some topics in textbooks. 
According to Tarmana and Kuran (2015), relating new knowledge to students' experiences assists students to understand the new concepts. It is therefore, imperative in Accounting to relate unique concepts to students' experience, and this is regarded as the fundamental strategy when introducing and clarifying new knowledge. Teachers pointed out that most textbooks fell short in guiding students by relating the content to their daily real life experiences. Consequently, it was challenging to introduce unfamiliar topics due to unique concepts and complex knowledge found in the subject. According to Terblanche and de Clercq (2020), students find it very difficult to master new knowledge if it is not related to their experiences as they may be unaware of the key learning points on each topic. This impacts negatively to students' conceptual understanding of the new content. As a result, teachers had to devise their own strategies of introducing the particular topics.

The use of visuals is crucial in emphasising new Accounting concepts and to understanding and retaining information (Stephenson, 2017; Sunday, 2014). Teachers were of the view that most textbooks succeeded in providing suitable graphics and other features to motivate learning and stimulate thinking while guiding the teacher, although pictures were not clear. This findings is supported by Sunday (2014) and Tarmana and Kuran (2015), who found that graphics should be included in textbooks in a manner that attracts, engages meaningfully and stimulates the imagination to promote students' understanding.

Accounting as a practical subject requires more activities to equip students with relevant skills. This means that assessment activities found in textbooks must cover the content of the subject as well as the range of skills to cater for students' different abilities (Barac \& du Plessis, 2014; Freahat \& Smadi, 2014). Teachers indicated that textbooks were lacking in providing enough activities. However, most textbooks had appropriate activities that allow students to engage in problem solving and creative thinking. This is contrary to Yang and Sianturi (2017) who found that mathematics textbooks had activities that mainly involve lower-order level questions. Furthermore, findings revealed that teachers were concerned that students were only involved in less structured problems as textbooks had no unfamiliar open-ended questions that require students to use deep processing critical thinking skills. Such questions often fail to expose students to unstructured and challenging financial problems.

Although textbooks were compatible with the curriculum, they fell short in guiding and supporting teaching and learning. However financial limitations hampered teachers from prescribing the textbooks with all the parameters of quality textbook. Furthermore, teachers found it hard to use only one textbook as they had flaws. Teachers ultimately relied on other resources like examination guidelines, annual teaching plan and past examination papers that encourages teachers to teach to test. 


\section{Conclusion}

This article sought to explore teachers' views on the quality of Accounting Grade 12 textbooks. Despite the teachers' views that all prescribed textbooks are compatible with the Accounting curriculum in terms of topic coverage, textbooks were found wanting in supporting and guiding teaching and learning of Accounting. While learning in Accounting is developmental and underpinned by the notion of a hierarchy of knowledge and skills, teachers revealed that the sequencing of content in the textbook is incompatible with the Accounting curriculum. This discrepancy may deny students the opportunity of learning everything that they should be learning. This may also confuse the novice teachers who often rely heavily on textbooks. Furthermore, teachers viewed some of the textbooks as unsuccessful in allowing students to grow gradually within the subject. As a result, teachers found it challenging to tailor lessons to the knowledge and interests of students. There was an outcry from teachers regarding the shortages of activities and poor questioning styles that do not cohere with the question style found in the external papers. In conclusion, it could be said that while textbooks continue to contribute to effective teaching and learning of Accounting, teachers also acknowledge their constraining or limiting factors in supporting teaching and learning. All participants expressed common views in terms of the deficiencies in the quality of Accounting grade 12 prescribed textbooks.

This study is limited in that the findings only represent the views of only ten teachers. Therefore findings cannot be generalised beyond this sample. Furthermore, the interview schedule or questions for interviews are likely to influence the findings as any inferences are circumscribed by and restricted to the information contained in them.

From the research findings, it may be noted that there is a potential for further research, especially a study in which teachers will be observed using textbooks in class. Moreover, more research will be needed to shed light on the broader scope of views on the quality of textbooks which could yield diverse results. There is a need to conduct a quantitative study with a large number of Accounting teachers. Subsequent research could include the views of Accounting learners to determine how they view their prescribed textbooks in terms of assisting them to achieve the learning outcomes they supposed to attain.

The recommendations offered to the writers of the textbooks are that it is better to modify or revise textbooks based on the characteristics of quality textbooks. To meet this requirement and overcome the above-mentioned deficiencies viewed by teachers in Accounting textbooks, the textbook writers must have an additional responsibility to ensure that the textbooks reflect the basic characteristics of quality textbooks. Since teachers seem to rely heavily on textbooks as teaching resources, textbook scrutiny is needed to analyse the contents of the textbook and to know the extent of quality of their textbooks. Teachers should also be included during evaluation process to identify issues related to textbooks effective use and suggesting strategies for improvement. 
The lacking guidance and support given to teachers and students by the prescribed textbooks, coerces teachers to rely heavily on other support materials that encourage teachers to teach to the examination. In trying to refraining from this habit, the teachers should be trained on teaching materials development. This will increase their knowledge of developing supplementary materials and adapting materials to suit their needs. This suggests that experienced teachers should develop their own resources, especially assessment activities, or turn to other sources such as the Internet to supplement textbooks. Teachers can also share materials and information with their colleagues from neighbouring schools or clusters. This may help teachers curb shortcomings identified in the prescribed textbooks. In addition, if the identified gaps in the textbooks can be addressed accordingly, teachers will gain more confidence in their prescribed textbooks and it will support their teaching greatly.

\section{References}

Abbott, J. I., \& Palatnik, B. R. (2018). Students' perceptions of their accounting class: Implications for instructors. Accounting Education, 27(1), 72-93. https:// doi.org/10.1080/09639284.2017.1381032

Adeoye, B. F., \& Olabiyi, O. S. (2011). Basic Technology Textbooks in Nigerian Secondary Schools. A Quality and Content Analysis, 14(2), 153-168.

Aggarwal, J. C. (2001). Principles, methods and techniques of teaching (2nd ed.). New Delhi, India: VIKAS publishing.

Arek-Bawa, O., \& Dhunpath, R. (2017). Assessment and Cognitive Demand in Higher Education Accounting Textbooks. Alternation, 24(2), 139-165. https:// doi.org/10.20853/34-1-3370

Barac, K., \& Du Plessis, L. (2014). Teaching pervasive skills to South African accounting students. Southern African Business Review, 18(1), 53-79. https://doi.org/10.25159/1998-8125/5645

Bargate, K. (2012). The readability of managerial accounting and financial management textbooks. Meditari Accountancy Research, 20(1), 4-20. https://doi.org/10.1108/10222521211234192

Bharath, P. (2015). An investigation of progression in historical thinking in South African History textbooks (Doctoral Thesis). University of KwaZulu-Natal: Pietermaritzburg.

Chirwa, G. W., \& Naidoo, D. (2016). Teachers' perceptions of the quality of the new Expressive Arts textbooks for Malawi primary schools. South African Journal of Childhood Education, 6(1), 1-10. https://doi.org/10.4102/sajce.v6i1.411

Cohen, L., Manion, L., \& Morrison, K. (2018). Research methods in Education (8th ed). New York: Routledge.

Creswell, J. W. (2014). Research design: Qualitative, quantitative, and mixed methods approaches (4th ed). London, England: Sage.

Davidson, R. A., \& Baldwin, B. A. (2005). Cognitive skills objectives in intermediate accounting textbooks: Evidence from end-of-chapter material. Journal of Accounting Education, 23(2), 79-95. https://doi.org/10.1016/j.jaccedu.2005.05.001

Department of Basic Education. (2011). Curriculum and Assessment Policy Statement. Grades 10-12. Accounting. Pretoria: Government Printers.

Department of Education. (2009). Report of the task team for the review of the implementation of the National Curriculum Statement. Pretoria: Government Printers. 
Erasmus, L. J., \& Fourie, H. (2018). Inclusive accountancy programmes in South African higher education: A revised teaching approach. Accounting Education, 27(5), 495512. https://doi.org/10.1080/09639284.2018.1507828

Fan, L. (2013). Textbook research as scientific research: towards a common ground on issues and methods of research on mathematics textbooks. ZDM, 45(5), 765-777. https://doi.org/10.1007/s11858-013-0530-6

Freahat, N. M., \& Smadi, O. M. (2014). Lower-order and higher-order reading questions in secondary and university level EFL textbooks in Jordan. Theory and Practice in Language Studies, 4(9), 1804-1813. https://doi.org/10.4304/tpls.4.9.1804-1813

Janko, T., \& Knecht, P. (2013). Visuals in Geography Textbooks: Categorization of Types and Assessment of Their Instructional Qualities. Review of International Geographical Education Online, 3(1), 93-110.

Kimmons, R. (2015). Open Education Resources (OER) quality and adaptation in K-12: Comparing teacher evaluations of copyright-restricted, open, and open/adapted textbooks. The International Review of Research in Open and Distributed Learning, 16(5), 39-57. https://doi.org/10.19173/irrodl.v16i5.2341

Liang, L., \& Cobern, W.W. (2013). Analysis of a typical Chinese high school biology textbook using the AAAS textbook standards. Eurasia Journal of Mathematics, $\begin{array}{llll}\text { Science } & \& & \text { Technology } & \text { 329-336. }\end{array}$ https://doi.org/10.12973/eurasia.2013.942a

Lee, J., \& Catling, S. (2016). Some perceptions of English geography textbook authors on writing textbooks. International Research in Geographical and Environmental Education, 25(1), 50-67. https:// doi.org/10.1080/10382046.2015.1106204

Lin, Y. C., \& Yang, D. C. (2015). Examining the Differences of Linear Systems between Finnish and Taiwanese Textbooks. Eurasia Journal of Mathematics, Science $\mathcal{E}$ Technology Education, 11(6), 1265-1281. https://doi.org/10.12973/eurasia.2015.1483a

Marshall, C., \& Rossman, G. B. (2014). Designing qualitative research (6th ed). London, England: Sage.

Morales, R., \& Baker, A. (2018). Secondary Students' Perceptions of Open Science Textbooks Secondary Students' Perceptions of Open Science Textbooks. Journal of Interactive Media in Education, 1(4), 1-9. https:// doi.org/10.5334/jime.455

Ngwenya, J., \& Arek-Bawa, O. (2019). Exploring the quality of Grade 12 accounting education textbooks. The Journal for Transdisciplinary Research in Southern Africa, 15(1), 1-10. https:// doi.org/10.20853/34-1-3370

Salam, N. H. A., \& Shahrill, M. (2014). Examining classroom interactions in secondary mathematics classrooms in Brunei Darussalam. Asian Social Science, 10(11), 92-103. http://dx.doi.org/10.5539/ass.v10n11p92

Schulze, S. (2003). Research methodology: Study Guide. Pretoria: University of South Africa.

Stephenson, S. S. (2017). Accounting Community of Practice pedagogy: a course management invention for developing personal competencies in accounting education. Accounting Education, 26(1), 3-27. https://doi.org/10.1080/09639284.2016.1247008

Sunday, A. S. (2014). Mathematics textbook analysis: A study on recommended mathematics textbooks in school use in the southwestern states of Nigeria. European Scientific Journal Special Edition, 1, 140-151.

Swanepoel, S. (2010). The assessment of the quality of science education textbooks: conceptual framework and instruments for analysis (Doctoral Thesis). University of South Africa, Pretoria.

Tarmana, B., \& Kuran, B. (2015). Examination of the cognitive level of questions in social studies textbooks and the views of teachers based on Bloom taxonomy. 
Educational Sciences: Theory $\mathcal{E}$ Practice, 15(1), 213-222. https:// doi.org/10.12738/estp.2015.1.2625

Terblanche, E. A. J., \& de Clercq, B. (2020). Factors to consider for effective critical thinking development in auditing students. South African Journal of Accounting Research, 34(2), 96-114. https:/ / doi.org/10.1080/10291954.2019.1669293

Yang, D. C., \& Sianturi, I.A. (2017). An analysis of Singaporean versus Indonesian textbooks based on trigonometry content. Eurasia Journal of Mathematics Science and Technology Education, 13(7), 3829-3848. https://doi.org/10.12973/ eurasia.2017.00760a

Yang, D., Wang, Z., \& Xu, D. (2015). A comparison of questions and tasks in geography textbooks before and after curriculum reform in China. Review of International Geographical Education Online, 5(3), 231-248. 